\title{
Morphometric analysis of Vu Gia - Thu Bon using GIS
}

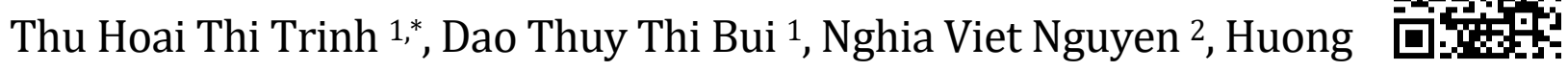 \\ Mai Dao ${ }^{1}$ \\ ${ }^{1}$ Faculty of Surveying, Mapping and Geographic Information, Hanoi University of Natural resources and \\ Environment, Vietnam \\ ${ }^{2}$ Faculty of Geomatics and Land Administration, Hanoi University of Mining and Geology, Vietnam
}

\section{ARTICLE INFO ABSTRACT}

Article history:

Received 21 $1^{\text {st } J u n e ~} 2020$

Revised 29th July 2020

Accepted 31 st Aug. 2020

\section{Keywords:}

DEM,

GIS,

Morphometric,

Vu Gia - Thu Bon.
The Vu Gia - Thu Bon river basin is one of the largest basins in Vietnam. Research and assessment of this potential basin is a great interest to scientists and regulators. One of the important studies is the evaluation of morphological parameters of the basin. The morphological parameters represent water resources and at the same time are one of the factors that help researchers give a comprehensive view of the basin, assessing the factors related to the direction of the flow, the flow rate or hazards throughout the basin. Therefore, this paper is an attempt to evaluate the morphology of Vu Gia - Thu Bon river basin using DEM SRTM (30 m) data in GIS. This analysis can be achieved through the measurement of linear aspects, aerial aspects and relief aspects of the drainage basin. The results of the study show that stream order ranges from first to sixth order with a total stream length of 1024, a total length of $3183.2 \mathrm{~km}$. Basin was divided into three subregions: upland, midland, and lowland. Those represent $66,9 \%, 26,0 \%$ and 7,1\% percent of the region's total area respectively.

Copyright (C) 2020 Hanoi University of Mining and Geology. All rights reserved.

${ }^{*}$ Corresponding author

E-mail: tththu@hunre.edu.vn

DOI: 10.46326/JMES.2020.61(4).03 


\title{
Tạp chí Khoa học Kỹ thuật Mỏ - Địa chất
}

Trang điện tử: http://tapchi.humg.edu.vn

\section{Ứng dụng GIS xác định hình thái lưu vực sông Vu Gia - Thu Bồn}

\author{
Trịnh Thị Hoài Thu ${ }^{1,{ }^{*}}$, Bùi Thị Thúy Đào ${ }^{1}$, Nguyễn Viết Nghĩa ${ }^{2}$, Đào Mai Hương ${ }^{1}$ \\ ${ }^{1}$ Khoa Trắc địa, Bản đồ và Thông tin địa lý, Trường Đại học Tài nguyên và Môi trường Hà Nội, Việt Nam \\ ${ }^{2}$ Khoa Trắc địa - Bản đồ và Quản lý đất đai , Trường Đại học Mỏ - Địa chất, Việt Nam
}

THÔNG TIN BÀI BÁO T TÓM TẮT

Quá trình:

Nhận bài 21/6/2020

Sưa xong 29/7/2020

Chấp nhận đăng 31/8/2020

Tù̀ khóa:

DEM,

GIS,

Hình thái,

Vu Gia - Thu Bồn.
Lưu vực sông Vu Gia - Thu Bồn là một trong nhũng lưu vực lớn nhất trong cả nước, việc thực hiện nghiên cúu đánh giá luu vực giàu tiềm năng này đang là mối quan tâm lớn của các nhà khoa học và các nhà quản lí. Một trong những nghiên cứu quan trong là việc đánh giá các thông số hình thái của lưu vực. Các thông số hình thái biểu thị nguồn tài nguyên nước và đồng thời là một trong những yếu tố giúp các nhà nghiên cúu có cái nhìn toàn diện về lưu vực, đánh giá các yếu tố liên quan tới hướng của dòng chảy, tốc độ dòng chảy hay các mối nguy co trên toàn lưu vực. Bài báo này được thực hiện nhằm xác định và đánh giá hình thái lưu vực sông Vu Gia - Thu Bồn dựa trên dũ liệu DEM SRTM (30 m) bằng công nghệ GIS. Việc đánh giá hình thái trong nghiên cúu này thông qua 3 nhóm tham số: tham số tuyến, tham số bề mặt và tham số địa hình. Kết quả của nghiên cúu cho dòng chảy của luu vực được phân thành 6 cấp với số thứ tự tăng tù̀ $1 \div 6$, với tông số dòng chảy là 1024 tương ứng với tổng chiều dài là $3183,2 \mathrm{~km}$, phân chia lưu vực thành 3 vùng: ha lưu với diên tích 70955,85 ha tương úng là 7,1\%; vùng trung lưu với diện tích 259176,3 ha chiếm 26,0\% và vùng thượng lưu với diện tích 668118,7 ha chiếm $66,9 \%$.

C 2020 Trường Đại học Mỏ - Địa chất. Tất cả các quyền được bảo đảm.

\section{Mở đầu}

Đặc tính hình thái học đóng một vai trò quan trọng cho sự hiểu biết về trạng thái địa chất, thủy văn và mạng lưới dòng chảy của lưu vực (Horton, 1945; Chorley và nnk., 1957; Reddy và nnk., 2004). Hình thái của lưu vực cung cấp không chỉ mô tả về cảnh quan mà còn là công cụ mạnh mẽ để định lượng các đặc tính lưu vực sông (Strahler,

*Tác giả liên hệ

E-mail: tththu@hunre.edu.vn

DOI: 10.46326/JMES.2020.61(4).03
1964). Phân tích hình thái là phép đo và phân tích toán học về hình dạng, kích thước, địa hình của lưu vực thông qua xác định một số tham số đặc trưng của lưu vực sông (Biswas và nnk., 1999; Nag và Chakraborty, 2003; Putty, 2007). Có nhiều loại tham số hình thái, được phân chia theo nhiều cách khác nhau. Điển hình như nghiên cứu của (Nagaraju và nnk., 2015) đã chia các tham số hình thái thành ba nhóm là đặc tính tuyến, đặc tính bề mặt và đặc tính gradient của mạng lưới dòng chảy. Nghiên cứu của (Nag và Chakraborty, 2003) lại chia các tham số hình thái thành bốn nhóm bao gồm: đặc tính tuyến, đặc tính bề mặt, đặc tính địa 
hình và đặc tính độ dốc. Hoặc các tham số được phân thành tham số cơ bản, tham số dẫn xuất và tham số hình dạng (Ibrahim Bathis và Ahmed, 2014). Tuy các tham số được phân theo nhiều cách nhưng tựu trung lại chúng đều xuất phát từ ba nhóm tham số đó là nhóm tham số tuyến, nhóm tham số bề mặt và nhóm tham số địa hình. Hình thái lưu vực sông có thể xác định bằng cách sử dụng các phương pháp truyền thống như quan sát thực địa và bản đồ địa hình. Tuy nhiên, phương pháp này vừa tốn thời gian và chi phí (Krishnamurthy và nnk., 1996; Nisha Sahu, 2017). Hiện nay, GIS được sử dụng rộng rãi trong các nghiên cứu tính toán các tham số hình thái, ưu điểm nổi bật của GIS là cung cấp một môi trường linh hoạt, lý tưởng và đồng thời cũng cung cấp các công cư phân tích như flow length (chiều dài dòng chảy), flow accumulation (tích tụ dòng chảy), flow direction (hướng dòng chảy) cho các phân tích không gian trong việc xác định các đặc trưng hình thái (Vincy và nnk., 2012; Ibrahim Bathis và Ahmed, 2014; Nisha Sahu và nnk., 2017). Mô hình số độ cao DEM đã được sử dụng nhiều trong nghiên cứu thủy văn, hình thái (Ibrahim Bathis và Ahmed, 2014; Nisha Sahu và nnk., 2017). Việc chiết tách các tham số hình thái từ DEM được đánh giá là hiệu quả và đảm bảo độ tin cậy (Moore và nnk 1991). Trên thế giới hiện nay có rất nhiều nguồn dữ liệu DEM toàn cầu, phổ biến là dữ liệu ASTER (30 m), SRTM (90 m), SRTM (30 m) và ALOS $(30 \mathrm{~m})$, theo đánh giá của (Burhan Niyazi và nnk., 2019) dữ liệu SRTM 30 m được sử dụng cho kết quả phân tích và chiết tách các thông số hình thái là tốt nhất tương đương với bản đồ địa hình tỉ lệ 1: 50000 . ̛̛̉ Việt Nam trong tiêu chuẩn quốc gia về tính toán các đặc trưng dòng chảy lũ (TCVN9845, 2013), hay trong Thông tư 12/2014/TT-BTNMT (TT12, 2014) về quy định kỹ thuật điều tra, đánh giá tài nguyên nước mặt có đề cập đến việc xác định một số tham số hình thái như một nhiệm vụ của công tác quản lý tài nguyên nước. Tuy nhiên, các công trình nghiên cứu ứng dụng GIS nhằm xác định các tham số hình thái tại Việt Nam đang bị bỏ ngỏ, đặc biệt với lưu vực lớn như Vu Gia - Thu Bồn. Từ những luận giải trên, bài báo này được thực hiện nhằm mô tả, đánh giá hình thái lưu vực sông Vu Gia -Thu Bồn từ nguồn dữ liệu DEM toàn cầu SRTM 30 m dựa trên GIS.

\section{Dũ liệu và khu vực nghiên cứu}

Vu Gia - Thu Bồn là một trong chín lưu vực lớn nhất tại Việt Nam, có tọa độ từ 14057'10" đến 16016'50" vĩ độ Bắc, 107053'50" đến 108012'20" kinh độ Đông (Hình 1), diện tích chủ yếu nằm ở tỉnh Quảng Nam và một phần của tỉnh Kon Tum và thành phố Đà Nẵng. Địa hình lưu vực này biến đổi khá phức tạp và bị chia cắt mạnh, địa hình có xu hướng nghiêng dần từ tây sang đông, có đầy đủ các kiểu cảnh quan địa hình từ kiểu núi cao phía tây, trung du ở giữa, dải đồng bằng và cồn cát ven biển (Tình, 2013).

Dữ liệu DEM được sử dụng là dữ liệu SRTM toàn cầu của NASA, dữ liệu được công bố cho khai thác miễn phí vào cuối năm 2015 trên USGS (https://www2.jpl.nasa.gov/srtm/). Trước đây, dữ liệu SRTM cho các khu vực bên ngoài Mỹ đã có độ phân giải là 3 giây tương ứng với khoảng $90 \mathrm{~m}$. Hiện nay, dữ liệu mới được đưa ra có độ phân giải 1 giây tương đương với $30 \mathrm{~m}$. Dữ liệu STRM được sử dụng trong nghiên cứu này là dữ liệu có độ phân giải $30 \mathrm{~m}$, hệ tọa độ sử dụng Ellipsoid WGS84, đơn vị độ cao là mét tính theo mực nước biển trung bình và được cắt theo tọa độ địa lý của lưu vực sông Vu Gia - Thu Bồn.

\section{Xác định hình thái lưu vực cho sông Vu Gia - Thu Bồn}

\subsection{Quy trình và phương pháp tính toán các tham số hình thái lưu vực sông}

Để xác định hình thái - hình học của lưu vực sông, việc đầu tiên là xác định dữ liệu cho toàn khu vực. Trước đây việc xác định hình thái - hình học được thực hiện trên dữ liệu khảo cứu ngoài thực địa hoặc dữ liệu từ bản đồ địa hình. Với công nghệ ngày nay, việc xác định hình thái - hình học được dựa trên mô hình số độ cao DEM. Sơ đồ tính toán hình thái - hình học lưu vực sông Vu Gia - Thu Bồn (Hình 2).

\section{Bước 1: Chuẩn hóa DEM}

Dũ liệu SRTM (30m) được lựa chọn cho xác định hình thái lưu vực thu thập trên (https:// earthexplorer.usgs.gov/) cho khu vực nghiên cứu. Dữ liệu sau khi thu thập đang ở hệ tọa độ địa lý trước khi đưa vào tính toán cần phải được chuẩn hóa. Chuẩn hóa dữ liệu DEM gồm 3 bước: chuyển đổi từ hệ tọa độ địa lý sang hệ tọa độ WGS 84 múi 48N, bước thứ hai hiệu chỉnh dữ liệu độ cao theo 

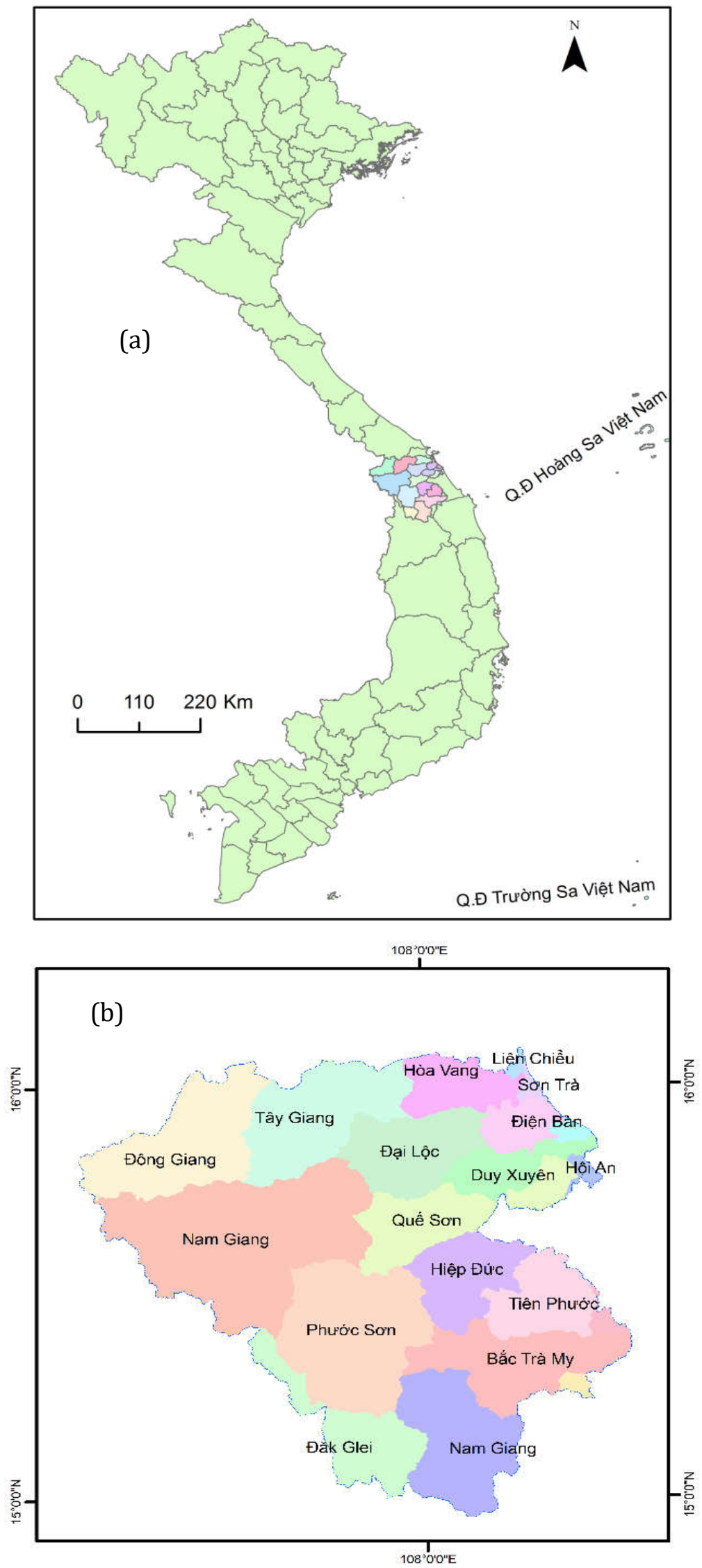


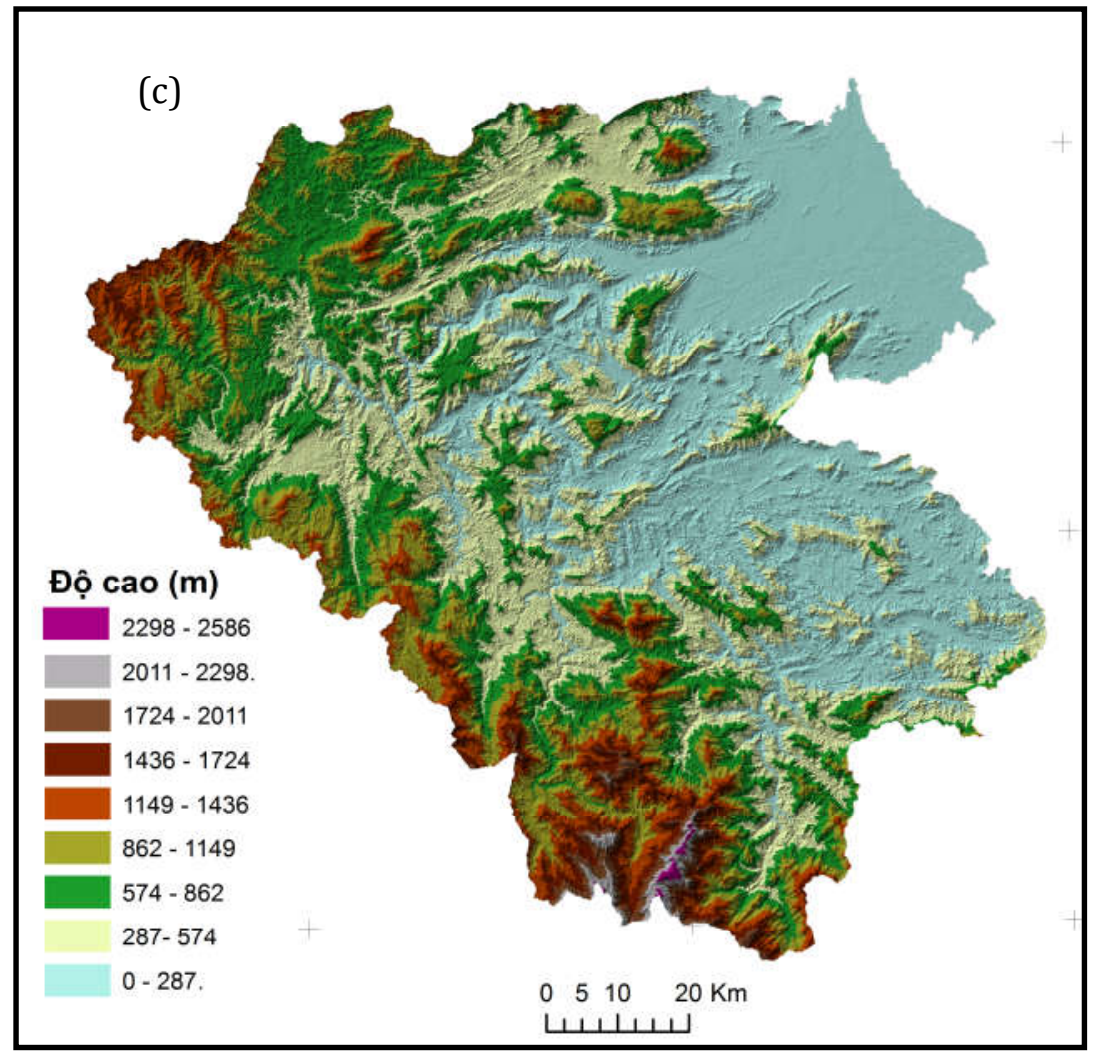

Hình 1. Lưu vực sông Vu Gia - Thu Bồn.

(a) Ranh giới hành chính Việt Nam (Tam và Thao, 2018); (b) Ranh giới hành chính lưu vực chiết xuất tù̀ DEM; (c) STRM DEM (30m) (https://earthexplorer.usgs.gov/).

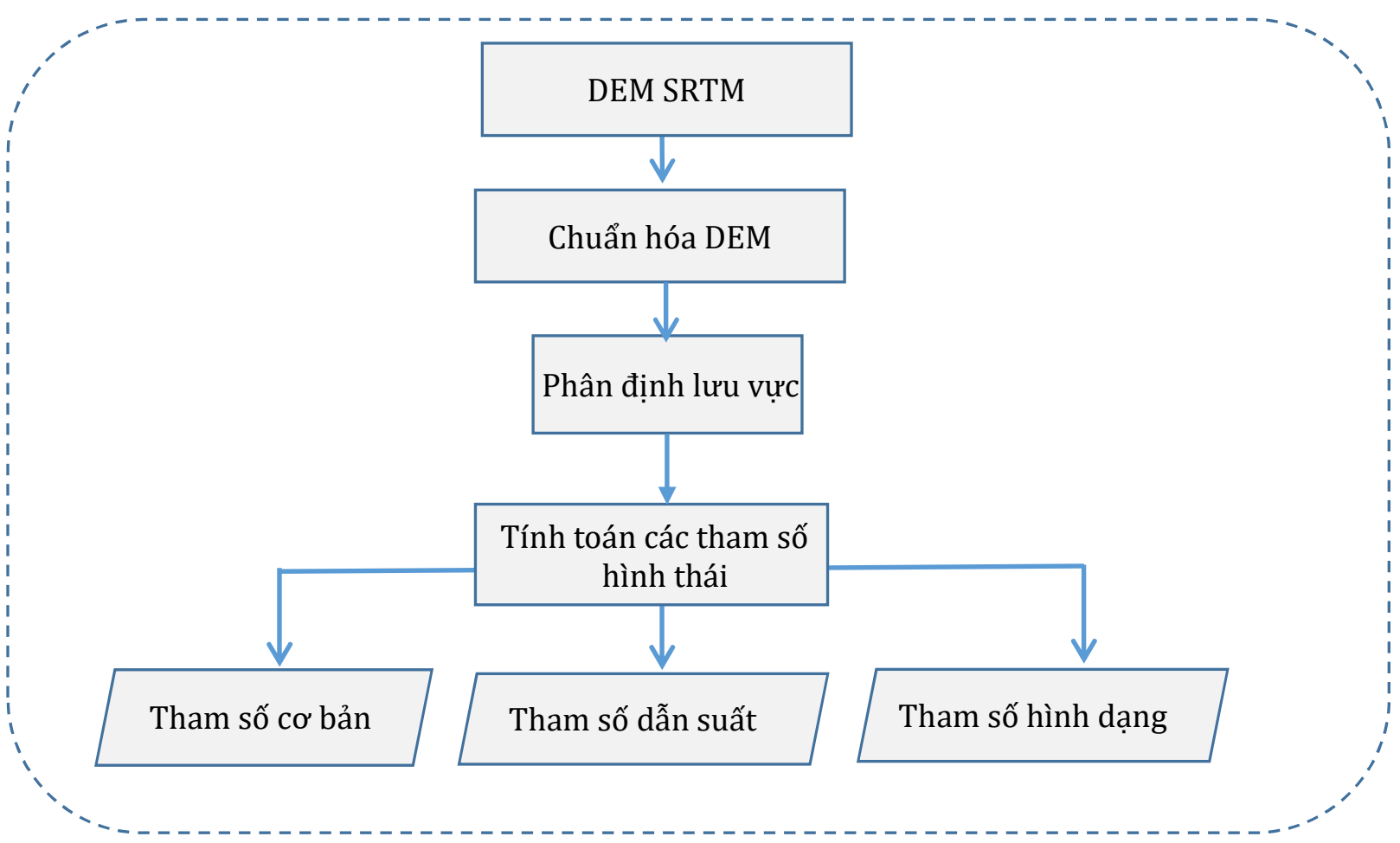

Hình 2. Sơ đồ xác định hình thái lưu vực sông Vu Gia - Thu Bồn. 
dữ liệu độ cao trên bản đồ địa hình tỷ lệ 1:50 000 tại khu vực, bước cuối cùng làm đầy những lỗi lõm sai so với địa hình thực tế, lỗi mất dữ liệu địa hình được thực hiện trên GIS. Kết quả sau hiệu chỉnh dữ liệu DEM được sử dụng cho các bước tính toán phân định lưu vực.

\section{Bước 2: Phân định lưu vực}

Phân định lưu vực sông là bước xác định bề mặt đất trong tự nhiên nơi mà lượng nước mưa khi rơi xuống sẽ tập trung và thoát ra một cửa xả. Các dữ liệu về tích lũy dòng chảy, hướng dòng chảy, mạng lưới dòng chảy, ranh giới lưu vực và lưu vực con sẽ được tạo ra trong quá trình phân định lưu vực trên GIS (Leilei, 2019). Diện tích toàn bộ lưu vực của khu vực nghiên cứu được xác định là $9982,5 \mathrm{~km}^{2}$.

\section{Bước 3: Tính toán các tham số hình thái}

Trong bước này tập trung xác định các tham số hình thái dựa trên cách tiếp cận về dạng tuyến, bề mặt và địa hình. Các tham số hình thái được xác định theo công thức (Bảng 1).

Bảng 1. Các tham số hình thái.

\begin{tabular}{|c|c|c|c|c|c|}
\hline $\mathrm{TT}$ & $\begin{array}{c}\text { Tham số hình } \\
\text { thái }\end{array}$ & Công thức & Mô tả & Đơn vị & Nguồn \\
\hline \multicolumn{6}{|c|}{ 1. Tham số tuyến } \\
\hline 1.1 & \begin{tabular}{|c|}
$\begin{array}{c}\text { Thứ tự dòng } \\
\text { chảy }(U)\end{array}$ \\
\end{tabular} & $U$ & Thứ tự dòng chảy được phân cấp & \begin{tabular}{|c|}
$\begin{array}{c}\text { Không thứ } \\
\text { nguyên }\end{array}$ \\
\end{tabular} & (Strahler, 1964) \\
\hline 1.2 & $\begin{array}{c}\text { Chiều dài } \\
\text { dòng chảy }\left(L_{u}\right)\end{array}$ & $L_{u}$ & $\begin{array}{l}\text { Tổng chiều dài dòng chảy của thứ } \\
\text { tự dòng chảy }(u)\end{array}$ & $\mathrm{km}$ & (Horton, 1945) \\
\hline 1.3 & $\begin{array}{l}\text { Chiều dài } \\
\text { trung bình } \\
\text { dòng chảy } \\
\left(L_{s m}\right)\end{array}$ & $L_{s m}=L_{u} / N_{u}$ & $\begin{array}{l}L_{u} \text { là tổng chiều dài dòng chảy của } \\
\text { thứ tự dòng chảy }(u) ; N_{u} \text { là tổng số } \\
\text { dòng chảy trong thứ tự dòng chảy } \\
u\end{array}$ & $\mathrm{~km}$ & (Strahler, 1964) \\
\hline 1.4 & $\begin{array}{l}\text { Tỉ số chiều dài } \\
\text { dòng chảy }\left(R_{l}\right)\end{array}$ & $R_{l}=L_{u} / L_{u-1}$ & $\begin{array}{l}L_{u-1} \text { là tổng chiều dài dòng chảy của } \\
\text { thứ tự dòng chảy thứ }(u-1)\end{array}$ & $\begin{array}{c}\text { Không thứ } \\
\text { nguyên }\end{array}$ & (Horton, 1945) \\
\hline 1.5 & $\begin{array}{l}\text { Tỉ lệ phân } \\
\text { nhánh }\left(R_{b}\right)\end{array}$ & $R_{b}=N_{u} / N_{u+1}$ & $\begin{array}{l}N_{u+1} \text { là tổng số dòng chảy trong thứ } \\
\text { tự dòng chảy }(u+1)\end{array}$ & $\begin{array}{c}\text { Không thứ } \\
\text { nguyên }\end{array}$ & $\begin{array}{l}\text { (Schumm, 1956) } \\
\text { (Horton, 1945) } \\
\end{array}$ \\
\hline 1.6 & $\begin{array}{c}\text { Chiều dài lưu } \\
\text { vực }\left(L_{b}\right)\end{array}$ & $L_{b}$ & Chiều dài dòng chảy lưu vực sông & $\mathrm{km}$ & \\
\hline \multicolumn{6}{|c|}{ 2. Tham số địa hình } \\
\hline 2.1 & $\begin{array}{l}\text { Địa hình lưu } \\
\text { vực }\left(B_{h}\right)\end{array}$ & $B_{h}=H-h$ & $\begin{array}{l}H \text { giá trị của điểm cao nhất; } h \text { giá trị } \\
\text { của điểm thấp nhất }\end{array}$ & $\mathrm{m}$ & \begin{tabular}{|c|} 
(Hadley và \\
Schumm, 1961) \\
\end{tabular} \\
\hline 2.2 & $\begin{array}{c}\text { Tỉ số địa hình } \\
\left(R_{r}\right)\end{array}$ & $R_{r}=B_{h} / L_{b}$ & & $\begin{array}{c}\text { Không thứ } \\
\text { nguyên }\end{array}$ & (Schumn, 1963) \\
\hline 2.5 & $\begin{array}{c}\text { Phân chia lưu } \\
\text { vực }\end{array}$ & & $\begin{array}{l}\text { Phân chia tiểu lưu vực, phân chia } \\
\text { theo địa hình và độ dốc }\end{array}$ & $\begin{array}{c}\text { Không thứ } \\
\text { nguyên }\end{array}$ & \\
\hline \multicolumn{6}{|c|}{ 3. Tham số bề mặt } \\
\hline 3.1 & \begin{tabular}{|c|} 
Diện tích lưu \\
vực $(A)$
\end{tabular} & & Diện tích toàn bộ lưu vực & $\mathrm{km}^{2}$ & \\
\hline 3.2 & \begin{tabular}{|c|}
$\begin{array}{c}\text { Mật độ mạng } \\
\text { lưới dòng } \\
\text { chảy }\left(D_{d}\right)\end{array}$ \\
\end{tabular} & $D_{d}=\sum L_{u} / A$ & $\begin{array}{l}L_{u} \text { là tổng chiều dài dòng chảy của } \\
\text { thứ tự dòng chảy }(u) ; A \text { là diện tích } \\
\text { toàn bộ lưu vực }\end{array}$ & $\mathrm{km} / \mathrm{km}^{2}$ & (Horton, 1945) \\
\hline 3.3 & \begin{tabular}{|c|} 
Tần suất dòng \\
chảy $\left(F_{s}\right)$
\end{tabular} & $F_{s}=N / A$ & $\begin{array}{l}N \text { là tổng chiều dài dòng chảy của } \\
\text { lưu vực }\end{array}$ & & (Horton, 1945) \\
\hline 3.4 & $\begin{array}{l}\text { Kết cấu lưu } \\
\text { vực }\left(R_{t}\right)\end{array}$ & $R_{t}=D_{d} \times F_{s}$ & $\begin{array}{l}D_{d} \text { là mật độ thoát nước; } F_{s} \text { là tần } \\
\text { suất dòng chảy }\end{array}$ & & (Smith, 1950) \\
\hline
\end{tabular}




\subsection{Kết quả nghiên cứu}

\subsubsection{Tham số tuyến}

Phân cấp dòng chảy $(U)$

Phân cấp dòng chảy chỉ mức độ phân nhánh trong một hệ thống sông. Có nhiều cách tiếp cận khác nhau đối với phân cấp trật tự topo của các con sông hoặc đoạn sông dựa trên khoảng cách từ nguồn (từ trên xuống) hoặc từ hợp lưu (điểm mà hai con sông hợp nhất) hay cửa xả (từ dưới lên). Trong nghiên cứu này sử dụng phương pháp phân cấp dòng chảy theo hệ thống "từ trên xuống" do Strahler đề xuất, theo đó các dòng sông được đặt thứ tự đầu tiên là các nhánh ngoài cùng. Nếu hai dòng chảy của cùng cấp hợp nhất, dòng chảy kết quả được cung cấp một số thứ tự cao hơn một cấp. Nếu hai con sông không cùng cấp hợp nhất, dòng chảy kết quả được đưa ra với số thứ tự cao hơn số thứ tự của hai con sông. Trong lưu vực sông Vu Gia
- Thu Bồn thứ tự dòng chảy được phân thành 6 cấp với tổng số lượng dòng chảy là 1024, trong đó nhiều nhất là dòng chảy cấp 1 với số lượng dòng chảy 513 và thấp nhất là cấp 6 với 7 dòng chảy (Bảng 2 và Hình 3 ).

\section{Chiều dài dòng chảy $\left(L_{u}\right)$}

Tham số này là một chỉ dẫn cho các quá trình phát triển địa mạo của các phân đoạn dòng chảy bao gồm phong hóa và kiến tạo của lưu vực sông $\mathrm{Vu}$ Gia - Thu Bồn. Phân tích cho thấy chiều dài dòng chảy có tỉ lệ nghịch với thứ tự dòng chảy (Bảng 1), thứ tự dòng chảy càng cao thì chiều dài càng thấp. Sự thay đổi này là do sự thay đổi độ cao dòng chảy và thành phần thạch học, độ dốc dòng chảy (Singh , 1997). Khi số lượng dòng chảy nhiều thì sẽ xảy ra hiện tượng biến đổi mạnh của bề mặt địa hình do xâm thực, dòng chảy càng ít thì bề mặt địa hình càng ổn hình (Zaidi, 2011).

Bảng 2. Tham số tuyến lưu vực sông Vu Gia - Thu Bồn.

\begin{tabular}{|c|c|c|c|c|c|c|}
\hline TT & $\begin{array}{c}\text { Phân cấp dòng } \\
\text { chảy }(U)\end{array}$ & $\begin{array}{c}\text { Tổng số dòng chảy } \\
\text { trong thứ tự dòng } \\
\text { chảy } u\left(N_{u}\right)\end{array}$ & $\begin{array}{c}\text { Chiều dài } \\
\text { dòng chảy } \\
\left(L_{u}\right)(\mathrm{km})\end{array}$ & $\begin{array}{c}\text { Chiều dài trung } \\
\text { bình dòng chảy } \\
\left(L_{s m}\right)(\mathrm{km})\end{array}$ & $\begin{array}{c}\text { Tỉ số chiều dài } \\
\text { dòng chảy }\left(R_{i}\right)\end{array}$ & $\begin{array}{c}\text { Tỉ lệ phân } \\
\text { nhánh }\left(R_{b}\right)\end{array}$ \\
\hline 1 & 1 & 513 & 1537,5 & 3,0 & $\mathrm{~N} / \mathrm{A}$ & 2,1 \\
\hline 2 & 2 & 239 & 774,5 & 3,2 & 0,5 & 1,6 \\
\hline 3 & 3 & 147 & 450,1 & 3,1 & 0,6 & 2,1 \\
\hline 4 & 4 & 70 & 226,4 & 3,2 & 0,5 & 1,5 \\
\hline 5 & 5 & 48 & 164,5 & 3,4 & 0,7 & 6,9 \\
\hline 6 & 6 & 7 & 30,2 & 4,3 & 0,2 & $\mathrm{~N} / \mathrm{A}$ \\
\hline 7 & & $\mathrm{~N}$ & $\sum L_{u}$ & $L_{s m}$ trung bình & $R_{i}$ trung bình & $\begin{array}{c}R_{b} \text { trung } \\
\text { bình }\end{array}$ \\
\hline 8 & & 1024 & 3183,2 & 3,1 & 0,5 & 2,8 \\
\hline
\end{tabular}

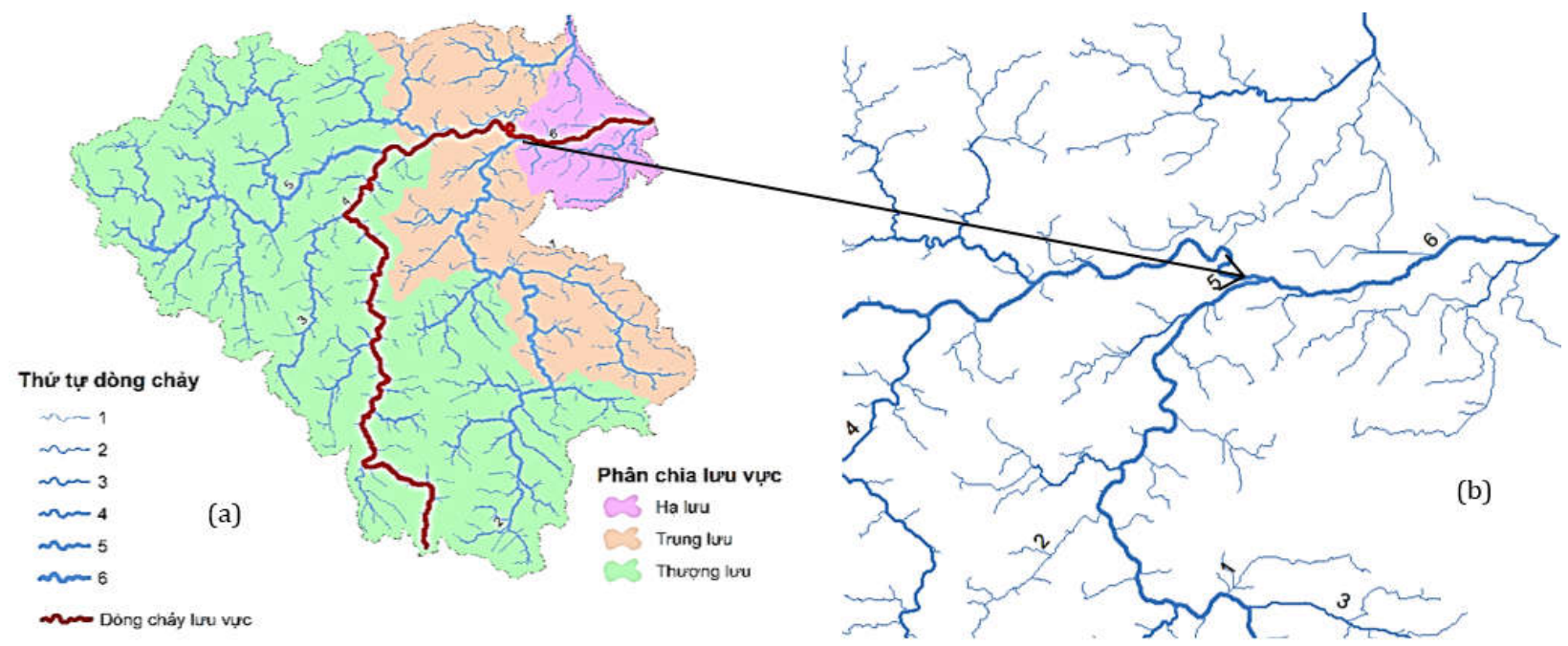

Hình 3. (a) Phân cấp dòng chảy toàn khu vực; (b) Phóng to thứ tự dòng chảy. 


\section{Chiều dài trung bình dòng chảy $\left(L_{s m}\right)$}

Chiều dài luồng trung bình là biểu hiện kích thước đặc trưng các thành phần của mạng lưới dòng chảy và bề mặt lưu vực liên quan (Strahler, 1964). Độ dài trung bình dòng chảy trong lưu vực sông Vu Gia - Thu Bồn nhìn chung là giảm từ bậc cao hơn xuống bậc thấp hơn với chiều dài tương ứng cho 6 cấp từ cao xuống thấp lần lượt là 4,3 ; 3,$4 ; 3,2 ; 3,1 ; 3,2$ và 3,0 .

\section{Tỉ số chiều dài dòng chảy $\left(R_{l}\right)$}

Được định nghĩa là tỉ số giữa độ dài dòng chảy thứ u với chiều dài của dòng chảy có thứ tự thấp hơn tiếp theo (Horton, 1945). Kết quả cho ra tỉ lệ chiều dài dòng chảy nằm từ $0,2 \div 0,7$. Các giá trị của tỉ số chiều dài dòng chảy được thể hiện chi tiết trong Bảng 2.

\section{Tỉ lệ phân nhánh $\left(R_{b}\right)$}

Theo Horton (1945) cho rằng đây là tham số quan trọng nhất trong đặc tính của lưu vực. Tỉ lệ phân nhánh có liên quan đến mô hình phân nhánh của mạng lưới dòng chảy và được xác định theo công thức 1.5 trong Bảng 1 . Nếu giá trị $R_{b}$ trong khoảng từ $3 \div 5$ thì cấu trúc địa chất không chi phối tới với mô hình thoát nước lưu vực sông. Nếu lớn hơn 5 thì biểu hiện sự kiểm soát về mặt cấu trúc địa chất tới mạng lưới thoát nước, và giá trị thấp hơn cho thấy không có bất cứ biến dạng nào trong mô hình thoát nước. Trong lưu vực sông Vu Gia Thu Bồn hầu hết các giá trị nằm trong khoảng từ 1,5 đến 2,1 cho thấy cấu trúc không ảnh hưởng tới mô hình thoát nước lưu vực, và giá trị 6,9 của thứ tự dòng chảy thứ 5 chỉ ra rằng bị biến dạng lớn nhất tại lưu vực sông Vu Gia - Thu Bồn.

\section{Chiều dài lưu vực $\left(L_{b}\right)$}

Được định nghĩa bởi nhiều nhà khoa học như (Schumm, 1956; Gregory và Walling, 1973; Gardiner, 1975; Cannon,1976). Trong nghiên cứu này sử dụng định nghĩa $L_{b}$ là chiều dài dài nhất của lưu vực được đo từ đầu nguồn đến điểm hợp lưu (Gregory và Walling, 1973). Trong lưu vực sông Vu Gia - Thu Bồn xác định từ điểm đầu nguồn phía Nam tới điểm hợp lưu gặp biển Đông về phía Đông Bắc. Chiều dài của lưu vực sông Vu Gia - Thu Bồn là 197,9 km (Bảng 3).

\subsubsection{Tham số địa hình}

Địa hình và đặc điểm của địa hình đóng một vai trò quan trọng trong sự phát triển thoát nước của lưu vực, dòng chảy bề mặt và dòng chảy dưới bề mặt, địa mạo. Có nhiều tham số khi nghiên cứu tiếp cận địa hình của lưu vực, trong nghiên cứu này chỉ xác định 2 tham số chính đó là địa hình lưu vực và tỉ số địa hình. Từ các tham số này kết hợp với độ dốc để phân chia lưu vực thành vùng thượng lưu, trung lưu và hạ lưu như Bảng 3.

Địa hình lưu vực $\left(B_{h}\right)$ là sự thay đổi độ cao giữa điểm cao nhất của lưu vực là $2586 \mathrm{~m}$ và điểm thấp nhất của lưu vực là $0 \mathrm{~m}$. Địa hình lưu vực được xác định là $2586 \mathrm{~m}$ và tỉ số địa hình $\left(R_{r}\right)$ bằng 13,1 .

\section{Phân chia lưu vực:}

Khi phân định lưu vực sông Vu Gia - Thu Bồn, ngưỡng diện tích khoảng lựa chọn 12000 ha cho việc xây dựng 43 lưu vực con. Lưu vực sông Vu Gia - Thu Bồn được phân chia dựa trên độ cao và độ dốc của các lưu vực con thành 3 vùng thượng lưu, trung lưu và hạ lưu theo nguyên tắc:

- Dựa vào giá trị độ cao tiến hành chia vùng lưu vực thành 3 ngưỡng độ cao vùng thấp, vùng cao và vùng trung bình với giá trị xác định theo phương pháp phân ngưỡng Natural Break (Jenks, 1967). Tương tự như vậy, đối với độ dốc dựa trên thông số thống kê của độ dốc trong khu vực kết hợp với phương pháp phân chia Natural

Break tạo ra 3 ngưỡng độ dốc là độ dốc thấp, độ dốc trung bình và độ dốc cao.

- Các khu vực thượng lưu, trung lưu, hạ lưu là những khu vực địa lí được phân bố liền mạch.

Kết quả phân vùng lưu vực được xây dựng được thể hiện trong (Hình 3a), diện tích phân vùng lưu vực được thể hiện trong Bảng 3 cho thấy các khu vực giảm dần từ thượng lưu xuống hạ lưu tương ứng với $66,9 \%$ diện tích khu vực thượng lưu, $26 \%$ diện tích khu vực trung nguồn và còn lại là $7,1 \%$ diện tích khu vực hạ lưu. Điều đó cho thấy thời gian truyền lũ và hình thành lũ ở trong khu vực hạ lưu chậm hơn do diện tích của thượng lưu lớn hơn nhiều so với hai khu vực còn lại.

\subsubsection{Tham số bề mặt}

Các thông số bề mặt như diện tích lưu vực $(A)$, mật độ thoát nước $\left(D_{d}\right)$, hệ số hình dạng $\left(F_{f}\right)$, tần suất dòng chảy $\left(F_{s}\right)$, kết cấu lưu vực $\left(R_{t}\right)$, được tính toán và kết quả thể hiện trong Bảng 4 .

Mật độ mạng lưới dòng chảy $\left(D_{d}\right)$ : Mật độ mạng lưới dòng chảy trong lưu vực từ lâu đã được công nhận là một đặc điểm địa hình có ý nghĩa cơ bản. 
Bảng 3. Tham số địa hình lưu vực sông Vu Gia - Thu Bồn.

\begin{tabular}{|c|c|c|c|c|c|c|c|c|c|c|c|}
\hline TT & $\begin{array}{l}\text { Lưu } \\
\text { vực }\end{array}$ & $\begin{array}{l}\text { Chiều dài } \\
\text { lưu vực } \\
\left(L_{b}\right)(\mathrm{km})\end{array}$ & $\begin{array}{l}\text { Địa hình } \\
\text { lưu vực } \\
\left(B_{h}\right)(\mathrm{m})\end{array}$ & $\begin{array}{c}\text { Tỉ số địa } \\
\text { hình } \\
\left(R_{r}\right)\end{array}$ & \begin{tabular}{|} 
Phân chia \\
theo độ \\
cao trung \\
bình của \\
các lưu \\
vực con
\end{tabular} & $\begin{array}{c}\text { Khoảng } \\
\text { cao trung } \\
\text { bình của } \\
\text { các lưu } \\
\text { vực con }\end{array}$ & \begin{tabular}{|} 
Phân chia \\
theo dộ \\
dốc trung \\
bình của \\
các lưu vực \\
con
\end{tabular} & $\begin{array}{c}\text { Khoảng } \\
\text { cao trung } \\
\text { bình của } \\
\text { các lưu } \\
\text { vực con }\end{array}$ & $\begin{array}{l}\text { Diện } \\
\text { tích }\end{array}$ & $\begin{array}{c}\text { Diện tích } \\
\text { (ha) }\end{array}$ & $\begin{array}{l}\text { Phần } \\
\text { trăm } \\
\text { diện } \\
\text { tích } \\
(\%)\end{array}$ \\
\hline \multirow{3}{*}{1} & \multirow{3}{*}{$\begin{array}{c}\text { Vu } \\
\text { Gia- } \\
\text { Thu } \\
\text { Bồn }\end{array}$} & \multirow{3}{*}{197,9} & \multirow{3}{*}{2586} & \multirow{3}{*}{13,1} & $\begin{array}{c}\text { Vùng thấp } \\
\text { trưng }\end{array}$ & $0 \div 287$ & $\begin{array}{l}\text { Vùng có độ } \\
\text { dốc nhỏ }\end{array}$ & $2,4 \div 10,8$ & Hạ lưu & 70955,85 & 7,1 \\
\hline & & & & & \begin{tabular}{|l|} 
Vùng độ \\
cao TB
\end{tabular} & $287 \div 808$ & $\begin{array}{l}\text { Vùng độ } \\
\text { dốc TB }\end{array}$ & $10,8 \div 31,1$ & $\begin{array}{l}\text { Trung } \\
\text { lưu }\end{array}$ & 259176,3 & 26,0 \\
\hline & & & & & Vùng cao & $8 \div 1554$ & $\begin{array}{l}\text { Vùng độ } \\
\text { dốc cao }\end{array}$ & $31,1 \div 43,8$ & $\begin{array}{c}\text { Thượng } \\
\text { lưu }\end{array}$ & 668118,7 & 66,9 \\
\hline
\end{tabular}

Bảng 4. Tham số bề mặt luu vực sông Vu Gia - Thu Bồn.

\begin{tabular}{|c|c|c|c|c|c|}
\hline TT & Lưu vực & $\begin{array}{c}\text { Diện tích lưu vực } \\
(A)\left(\mathrm{km}^{2}\right)\end{array}$ & Mật độ thoát nước $\left(D_{d}\right)$ & $\begin{array}{c}\text { Tần suất dòng } \\
\text { chảy }\left(F_{s}\right)\end{array}$ & $\begin{array}{c}\text { Kết cấu lưu vực } \\
\left(R_{t}\right)\end{array}$ \\
\hline 1 & Vu Gia - Thu Bồn & 9982,5 & 0,3 & 0,1 & 3 \\
\hline
\end{tabular}

Nó là một biểu hiện của sự gần gũi hoặc khoảng cách của các kênh (Horton, 1932). Xác định $D_{d}$ là một phép đo số hữu ích của phân tích cảnh quan và tiềm năng dòng chảy (Chorley, 1969). $D_{d}$ của lưu vực sông $\mathrm{Vu}$ Gia - Thu bồn là $0,3 \mathrm{~km} / \mathrm{km}^{2}$ cho thấy mật độ mạng lưới dòng chảy trong khu vực nghiên cứu là tương đối thấp.

Tần suất dòng chảy $\left(F_{s}\right)$ giống như mật độ thoát nước, tần số dòng chảy cũng là một trong những thông số hình thái quan trọng và đối với lưu vực sông Vu Gia - Thu Bồn, giá trị 0,1 là thấp.

\section{Kết luận}

Kết quả phân tích của lưu vực thông qua 3 nhóm tham số: tham số tuyến, tham số địa hình và tham số bề mặt Tổng số dòng chảy là 1024 với chiều dài $3183.2 \mathrm{~km}$ phân thành 6 cấp, giá trị $R_{b}$ trung bình của lưu vực là 2.8 cho thấy rằng cấu trúc lưu vực không ảnh hưởng đến mô hình thoát nước. Về mặt địa hình, lưu vực chia thành 3 vùng thượng lưu, trung lưu và hạ lưu với diện tích tương ứng 668118.7 ha; 259176.3 ha và 70955.8 ha, qua phân tích cũng cho thấy mật độ dòng chảy của lưu vực này là thấp.

Đối với lưu vực rộng lớn như lưu vực Vu Gia Thu Bồn, việc phân tích có hệ thống các tham số hình thái với trong lưu vực sông Vu Gia - Thu Bồn từ dữ liệu STRM 30 m trên GIS có thể cung cấp giá trị quan trọng trong việc tìm hiểu các đặc điểm lưu vực. Các thông số được trích xuất sẽ là một tài liệu tham khảo hữu ích hỗ trợ công tác quản lí cũng như nghiên cứu khoa học chuyên sâu về lưu vực sông Vu Gia - Thu Bồn. Tuy nhiên, tùy thuộc vào quy mô lưu vực nghiên cứu mà lựa chọn mô hình số toàn cầu có độ phân giải không gian phù hợp. Trước khi thực hiện chiết tách dữ liệu dòng chảy cần phải đánh giá sự phù hợp của dữ liệu và độ chính xác của dữ liệu DEM với quy mô nghiên cứu.

\section{Lời cảm ơn}

Bài báo được thực hiện dưới sự hỗ trợ nghiên cứu của đề tài mã số: TNMT.2017.02.05 do Trường Đại học Tài nguyên và Môi trường Hà Nội chủ trì.

\section{Tài liệu tham khảo}

Biswas, S., Sudhakar, S. and Desai, V. R., (1999). Prioritisation of Sub-watersheds based on Morphometric Analysis of Drainage Basin: A Remote Sensing and GIS Approach. Journal of the Indian Society of Remote Sensing 27 (3), 155-166.

Burhan Niyazi, Syed Zaidi \& Milad Masoud, (2019). Comparative Study of Different Types of Digital Elevation Models on the Basis of Drainage Morphometric Parameters (Case Study of Wadi Fatimah Basin, KSA). Earth Systems and Environment 3, 539-550.

Cannon, J. P., (1976). Generation of explicit parameters for a quantitative geomorphic 
study of the Mill Creek Drainage Basin. Oklahoma Geology notes 36(1), 13-17.

Chorley, R. J., Donald-Malm E. G. and Pogorzelski H. A, (1957). A new standard for estimating drainage basin shape. American Journal of Science 255(2), 138-141.

Chorley, R. J., (1969). Introduction to fluvial processes. London: Methuen and Co. Limited (Pub.), 588.

Gardiner, V., (1975). Drainage Basin Morphometry. British Geomorphological Research Group Technical Bulletin 14, 48-50.

Gregory, K. J. and Walling, D. E., (1973). Drainage basin form and processes: A geomorphological approach. E. Arnold, ed. New York: Halsted Press. 456.

Hadley R. F. and Schumm S. A., (1961). Sediment sources and drainage basin characteristics in upper Cheyenne River Basin. U.S. Geological Survey Water-Supply Paper. 1531-B, 198.

Horton, R. E., (1932). Drainage-basin characteristics. Eos. Transactions American Geophysical Union 13(1), 350-361

Horton, R. E., (1945). Erosional development of streams and their drainage basins; hydrophysical approach to quantitative morphology. Geological Society of America 56, 275-370.

Ibrahim Bathis. K. and S. A. Ahmed, S. A., (2014). Evaluation of Morphometric Parameters - A comparative study from Cartosat DEM, SRTM and SOI Toposheet in Karabayyanahalli subwatershed, Karnatak., International Journal of Research (IJR) 1(11).

Jenks George, F., (1967). The Data Model Concept in Statistical Mapping. International Yearbook of Cartography 7. 186-190.

Krishnamurthy J., Srinivas G., Jayaram V., Chandrasekhar M. G., (1996). Influence of rock type and structure in the development of drainage networks in typical hard rock terrain. ITC J 3/4, 252-259.

Leilei Li, Jintao Yang and Jin Wu, (2019). A Method of Watershed Delineation for Flat Terrain Using Sentinel-2A Imagery and DEM: A Case
Study of the Taihu Basin. International Journal of Geo - Information 8, 258.

Moore, I. D., Grayson, R. B., Ladspm, A. R., (1991). Digital terrain modelling: a review of hydrological, geomorphological and biological applications. Hydrol Process 5, 3-30.

Nag, S. K. and Chakraborty, S., (2003). Influence of rock types and structures in the development of drainage network in hard rock area. Journal of the Indian Society of Remote Sensing 31 (1), 25-35.

Nagaraju, D., Siddalingamurthy, D., Balasubramanian, S., Lakshmamma, A. and Sumithra S., (2015). Morphometric analysis of Byramangala Watershed, Bangalore Urban District, Karnataka, India. International Journal of Current Engineering and Technology 5(3).

Ngô Đạt Tam, Nguyễn Quý Thao, (2018). Atlat địa lý Việt Nam. Nhà xuất bản giáo dục Việt Nam.

Nisha Sahu, G. P. Obi Reddy, Nirmal Kumar, M. S. S. Nagaraju, Rajeev Srivastava \& S. K. Singh., (2017). Morphometric analysis in basaltic Terrain of Central India using GIS techniques: a case study. Applied Water Science 7, 24932499.

Pakhmode, V., Kulkarni H., and Deolankar S., (2003). Hydrological-drainage analysis in watershed-programme planning: a case from the Deccan basalt, India. Hydrogeology Journal 11(5), 595-604.

Putty, M. R. Y., (2007). Quantitative geomorphology of the upper Kaveri basin in Western Ghats, in Karnataka. IE(I) Journal-CV 88, 44-49.

Reddy, G. P. O., Maji A. K., and Gajbhiye K. S. (2004). Drainage morphometry and its influence on landform characteristics in a basaltic terrain, Central India-a remote sensing and GIS approach. International Journal of Applied Earth Observation and Geoinformation 6(1), 116.

Schumm, S. A., (1956). Evolution of drainage systems and slopes in badlands at Perth Amboy, New Jersey. Geological Society of America Bulletin 67, 597- 646 
Schumm, S. A., (1963). Sinuosity of alluvial rivers on the Great Plains. Geological Society of America Bulletin. 74, 1089-1100.

Singh, S. and Singh, M. C. (1997). Morphometric Analysis of Kanhar River Basin. National Geographical Journal of India, 43 (1), 3143.from the Gagas River Basin, India. Journal Geological Society of India 77, 160-166.

Smith, K. G., (1950). Standards for grading textures of erosional topography. American Journal of Science 248, 655-668.

Strahler, A. N., (1964). Quantitative geomorphology of drainage basins and channel networks. Handbook of Applied Hydrology. McGraw-Hill. New York, 4-11

TCVN 9845, (2013). Tiêu chuẩn quốc gia. Tính toán các đặc trưng dòng chảy lũ.

Thông tư số 12 /2014/TT-BTNMT. Quy định kỹ thuật điều tra, đánh giá tài nguyên nước mặt.

Trần Văn Tình, (2013). Xây dựng bản đồ ngập lụt vùng hạ lưu lưu vực sông $\mathrm{Vu}$ gia - Thu bồn. Luận văn thạc sĩ. Trường đại học Khoa học Tự nhiên.

Vincy, M. V., Brilliant Rajan, M. V., and Pradeepkumar A. P., (2012). Geographic information system-based morphometric characterization of sub-watersheds of Meenachil river basin, Kottayam district, Kerala, India. Geocarto International.

Zaidi, F. K., (2011). Drainage Basin Morphometry for Identifying Zones for Artificial Recharge: A Case Study. 